\title{
Design and Realization of a Surgical Aspirator
}

\author{
${ }^{1}$ Pierre Louis Morpoo Rebeca, ${ }^{2}$ Thierno Ibrahima Barry, ${ }^{3}$ Ansoumane Sakouvogui, ${ }^{4}$ Cellou Kanté, \\ ${ }^{5}$ Mohamed Salif Camara, ${ }^{6}$ Daniel Mamy \\ ${ }^{1,2,6}$ Biomedical Equipment Technology Department, Mamou Higher Institute of Technology, Guinea \\ ${ }^{3,4}$ Energy Department, Higher Institute of Technology of Mamou, Guinea \\ ${ }^{5}$ Instrumentation and Physical Measurements Department, Higher Institute of Technology of Mamou, Guinea
}

\begin{abstract}
This study was carried out in the laboratories of the Biomedical Equipment Technology and Instrumentation and Physical Measurements departments of the Higher Institute of Technology of Mamou. The methodology adopted in this work is based on embedded systems technology. Its objective is the Design and Production of a surgical aspirator. The main results obtained during this work relate to the realization of the electrical diagrams of the power supply, the motherboard, the operation of the algorithm, the determination of the technical characteristics of the vacuum cleaner, the synoptic diagram of operation and the principle of operation. The improvement and popularization of this present device would make it possible to equip the various health structures of the country with surgical aspirators locally at a lower cost.
\end{abstract}

Keywords: Vacuum cleaner, Surgery, Patient, Design, Realization, Prototype.

\section{INTRODUCTION}

Surgical aspirators are used during and after procedures to remove surgical fluids, tissue, gases and fluids from the body. During surgery, care must be taken at all times that fluids can be aspirated quickly and reliably. This is what gives doctors a free view of the field of operation, so that the patient's health is not endangered. During long-term operations with a high production of liquids, it is necessary to be able to have a quick and quietest suction possible [1].

Surgical aspirators are used in a large number of surgical procedures: surgical suction, liposuction, cosmetic surgery, obstetric assistance, gastroenterology, endoscopy, ophthalmology, dermatology, neurosurgery, cardiac, thoracic, vascular surgery, etc. [2]-[3].The absence of a surgical suction pump in an operating theater can lead to serious errors. It is with this in mind that the first vacuum cleaner by Georges Dieulafoy was created in the 1869s [4].Nowadays, there are two types of surgical aspirators available in version mobile, (mounted on casters or not) that will be chosen according to the envisaged applications and usage constraints. In both cases, the power supply is on the mains, and the automatic operation and / or by pneumatic triggering (pedal) these are: the vacuum cleaner operating by means of an electric vacuum pump integrated into the device and the vacuum cleaner connected to central vacuum, available in the operating room by plug wall mounted with vacuum regulation by vacuum regulator [5].

The main important characteristics to take into account when choosing a model vacuum cleaner are as follows: the vacuum level (depression) which varies from 150 to 1000 mbar, the suction power (or flow rate) which varies between $50 \mathrm{l} / \mathrm{min}$ and $80 \mathrm{l} / \mathrm{min}$; the possibility of regulation; the presence of a security level (shutdown of the device in the event of overflowing of the jars, presence of the antibacterial filter, etc.); the capacity and graduation of associated jars from 1 to 5 liters in general [6].

The evolution of surgical suction pump technology has seen a very significant advance, which marked a symptomatic turning point in the history of surgical medicine. Faced with this considerable advance, the various advantages and disadvantages linked to models of surgical aspirators are structured into two main families, namely: from 1839 to 1980 and from 1980 to the present day. The comparison criteria are among others: the capacity (maximum amount of vacuum reached), flow rate, energy, vacuum setting and mobility [7].

In Guinea, the health system is experiencing enormous problems due to the lack of modern medical devices. Those existing on the market are sometimes very complex to maintain correctly, poorly adapted for some to our environment or quite simply very expensive for others. Among these devices, one of the most important for ensuring the suction of body fluids lacking in our hospitals, especially those in the interior of the country is the surgical suction device [8].

Likewise, most of the existing vacuum cleaners in our health facilities do not have an energy storage battery and have a low liquid collection capacity. What is however necessary for hospitals. Hence the goal of the present study, which consists of designing and producing a prototype of a surgical aspirator, which can perform suction in a simple manner over a long period, with energy autonomy, use in 
several departments, thanks to its mobility and marketing at an affordable cost.

\section{MATERIALS AND METHODS}

\subsection{Materials}

\section{a. Work tools}

For the realization of this present work the following tools were used: soldering irons, cruciform screwdrivers, the drill, the test plate, the pins, the tin, the pair of scissors, the pins, the adhesive tape, the pair of gans, the sandpaper, the centimeter, the multimeter, the glue, the saw blade, the screwdriver kit, the cutter. The assembly materials of the device are: glass, plywood, for mica, rubber jar and flexible and transparent rubber tubing.

\section{b. Electronic components used}

The electronic components used are: the Arduino board, the fuse, the transformer, the resistors, the capacitors, the diode, the relay, the Light-emitting Diode (LED) or Lightemitting diode (LED), the Liquid Crystal Display (LCD), the 7812 voltage regulator, the MOA-V143-AA motor, the ultrasonic sensor, the LM35 temperature sensor, and the buzzer or beeper.

\subsection{Methods}

The methodology adopted for carrying out this work is based on embedded systems technology. The Arduino Uno type board was used, it consists of: microcontroller, $\mathrm{HE}$ connectors, digital pins D0 to D13, analog output and power pins, USB connector, LED and reset button. The microcontroller (brain or heart of the card), is an ATmega328, it receives the program, stores it and executes it. From the program, it makes the LEDs flash, displays the characters on a screen, sends data to a computer, starts or stops the engine. The HE connectors are the support of the microcontroller. It connects all the pins of the ATmega328 circuit to connectors soldered on the edges of the board. They are divided into three main groups: digital pins, analog input pins, and power pins.

Digital pins D0 to D13 send and receive digital signals, analog pins receive analog values, analog outputs are simulated by digital pins and power pins (Vin and GND). The Vin pin (input voltage), is the current source equivalent to that used by the power connector (12V). The GND pins (Ground or Earth) are used to close the circuit. The USB connector allows you to connect a cable for data transfers, but also for its own power supply. The Power Jack is the external power port to meet power needs beyond the possibilities of the USB port. There are four LEDs L, RX, TX and ON. The reset button allows you to reset or stop the Arduino board.
The fuse (circuit breaker) serves as a circuit safety device against possible electrical overloads. Two 220V/110V stepdown and $220 / 12 \mathrm{~V}$ or 220/24 mid-point transformers were used. Electrical resistors are dipoles that oppose the flow of electric current. The capacitors are used to store electric charges on the armatures, they are electric voltage reservoirs, we used a dry capacitor for voltage filtering and an electrolytic capacitor for voltage smoothing.

The diodes have been used to transform alternating current and voltage into direct current and voltage and on the other hand to protect certain components. The relay made it possible to separate the power part and the control part. Light Emitting Diodes (LED) emits light when an electric current passes through them. LED D1 is connected to the main circuit, LED D2 is connected to the pin of the Arduino, and LED D3 is connected to the pin of the Arduino. The 16x2 Liquid Crystal Display (LCD) was used to display the level and temperature of the liquid collected in the jar. This $16 \times 2$ display consists of 16 pins which are: VSS (ground pin), VDD (positive power supply pin), VEE (display contrast adjustment pin), RS (register select pin), RW (read or write pin), E (enable input pin), D0 to D7 (bidirectional data bus pins), A (backlight anode pin) and $\mathrm{K}$ (backlight cathode ).7812 voltage regulator was used for protection, its characteristics are: output voltage $12 \mathrm{~V}$, maximum output current $1.5 \mathrm{~A}$, maximum input voltage $3.5 \mathrm{~V}$, number of pins 3 , minimum operating temperature $0 \mathrm{oC}$, number output 1 , and quiescent current $8 \mathrm{~mA}$. It is made up of three pins (the 1st In or Input pin for power, the 2nd pin tied to ground and the 3rd Out or Output pin is the Arduino board's power pin) [9].The MOA-V143-AA type single-phase vacuum motor was used as a compressor or vacuum pump for maximum versatility. It is characterized by a voltage of $115 \mathrm{~V}$, a current of $2.1 \mathrm{~A}$, a mechanical power of $0.09 \mathrm{~kW}$ and a maximum vacuum pressure of 200mbars. An HC-SRO4 ultrasonic sensor was used to detect the noise level in a range of $2 \mathrm{~cm}$ to $400 \mathrm{~cm}$. It is composed of a transmitter and a receiver [10].The LM35 type temperature sensor is used to locate the temperature in a range of $-55 \mathrm{oC}$ to $150 \mathrm{oC}$. It consists of three pins: the 1 st VCC is the sensor power pin (+ $5 \mathrm{~V})$, the 2nd OUT transmits the analog temperature information to the Arduino board and the 3rd GND 'is the ground pin. The buzzer or beeper with direct voltage was used for the alarm to signal that the liquid collection jar is full [11].

\section{RESULTS AND DISCUSSIONS}

The results obtained during this work relate to the realization of the electrical diagrams of the power supply, the motherboard, the operation of the algorithm, the determination of the technical characteristics of the vacuum cleaner, the synoptic diagram of operation and the principle operating. 
ISSN (online): 2581-3048

\subsection{Electrical diagram of the power supply}

Guinea's electricity sector supplies an alternating voltage of $220 \mathrm{~V}$ and a frequency of $50 \mathrm{~Hz}$ to the vacuum cleaner. Once this voltage passes through the protection fuse, it supplies the two branches of the circuit in parallel. In the first branch, voltage passes through the primary winding of the step-down transformer. Then, it passes through the secondary winding of said transformer through self-induction phenomena, which in turn lowers this input voltage from $220 \mathrm{~V}$ to $12 \mathrm{~V}$ AC. This alternating output goes to a diode bridge made up of four (4) diodes which provide rectification (transformation into a direct voltage of $12 \mathrm{~V}$ ).

This DC voltage containing parasitic frequencies from the source is in the first position smoothed by a dry capacitor (C1), and then the low ripple amplitudes are eliminated by an electrolytic capacitor (C2). After these two capacitors, is placed a voltage regulator (7812) which ensures the constant maintenance of the output voltage. This regulator is then mounted in parallel with an ordinary diode to ensure its protection against possible disturbances. After this regulator are also two capacitors one dry (C3) and electrolytic (C4) which respectively provide the second smoothing and filtering for more voltage stability. A testimonial LED that indicates the voltage of $12 \mathrm{~V}$ at the output of the power supply is in series with a protective resistor. This $12 \mathrm{~V}$ output voltage will thus be used to power the Arduino board and the switching relay.

In the second branch (which takes its source after the protection fuse), the voltage of $220 \mathrm{~V}$ passes through the first winding of the step-down transformer, then to the second winding by the phenomenon of self-induction which transforms this voltage of $220 \mathrm{~V}$ into $115 \mathrm{~V}$ alternating, provides the power required for the operation of the vacuum cleaner motor via the control pedal which is a push button.
This electrical diagram of the power supply is shown in Figure 1 .

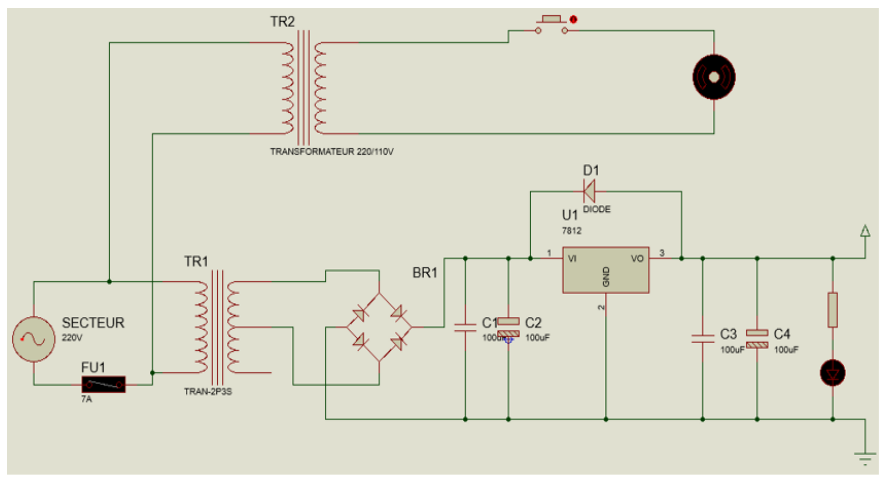

Figure 1: Electrical diagram of the vacuum cleaner power supply

\subsection{Circuit diagram of the motherboard}

The main element of this diagram is the motherboard whose component essentially is the Arduino board driven by a microcontroller which represents the brain of the system. It is the order of the shareholders who are as follows:

- The HC-SRO4 ultrasonic sensor gives information to the microcontroller and in turn gives the instruction in relation to the level of the liquid in the jar;

- The LM35 temperature sensor provides information to the microcontroller which in turn gives the instructions in relation to the temperature of the liquid collected in the jar;

- The 16x2 series of LEDs allow the level and temperature of the liquid in the jar to be displayed progressively and to indicate that the vacuum cleaner has been switched on;

- The buzzer signals the maximum level of the liquid reached $4000 \mathrm{ml}$ in the jar. This entire process is illustrated in Figure 2.

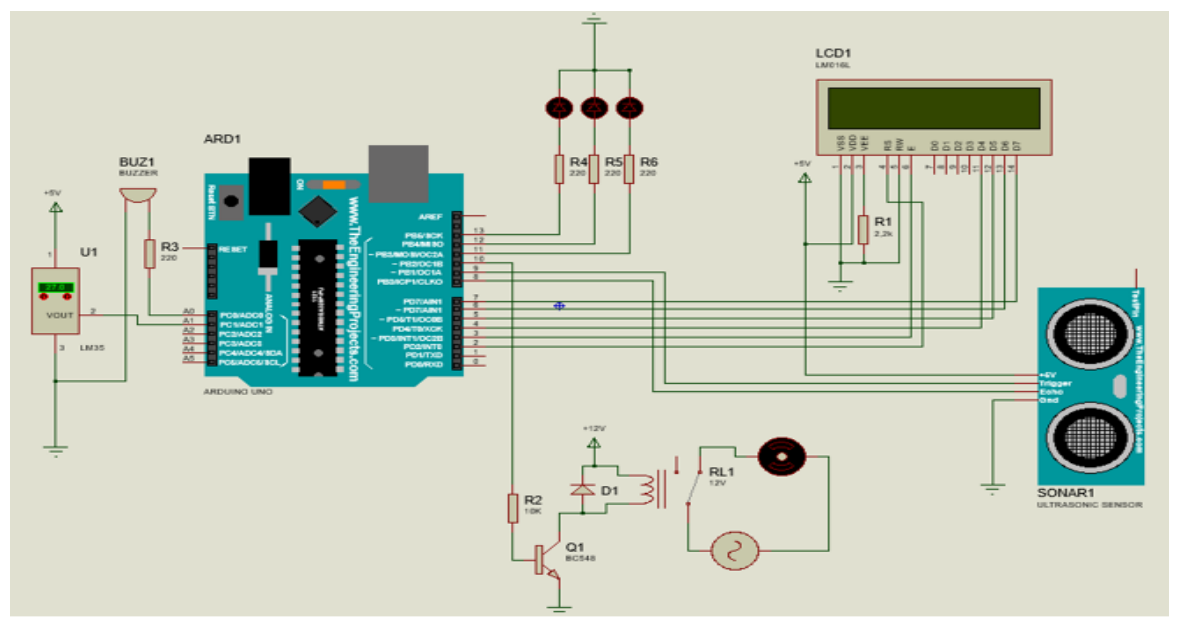

Figure 2: Electrical diagram of the motherboard 
ISSN (online): 2581-3048

\subsection{Operating algorithm}

The operation of the vacuum cleaner is shown schematically by the algorithm in Figure 3.

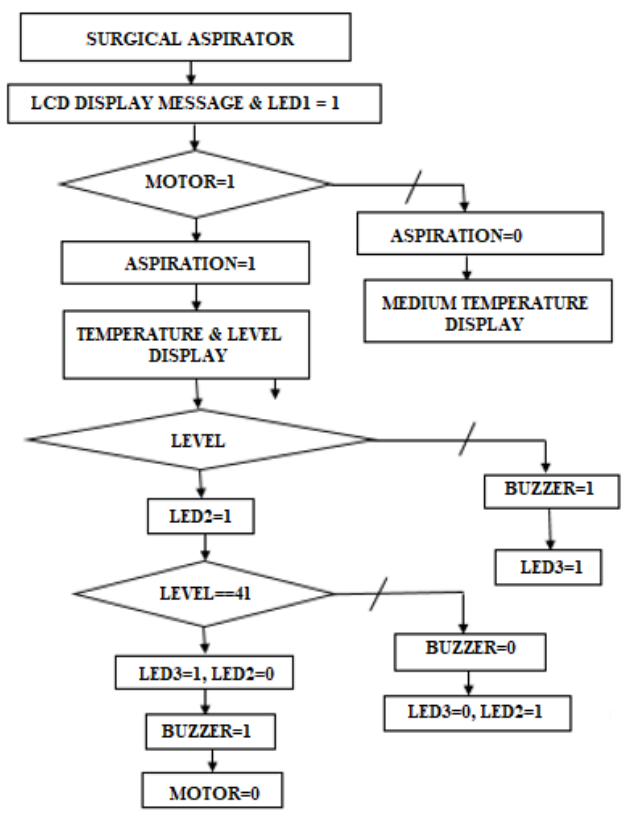

Figure 3: Diagram of how the algorithm works

\subsection{Block diagram of operation}

The synoptic diagram of the operation of the vacuum cleaner is given in Figure 4.

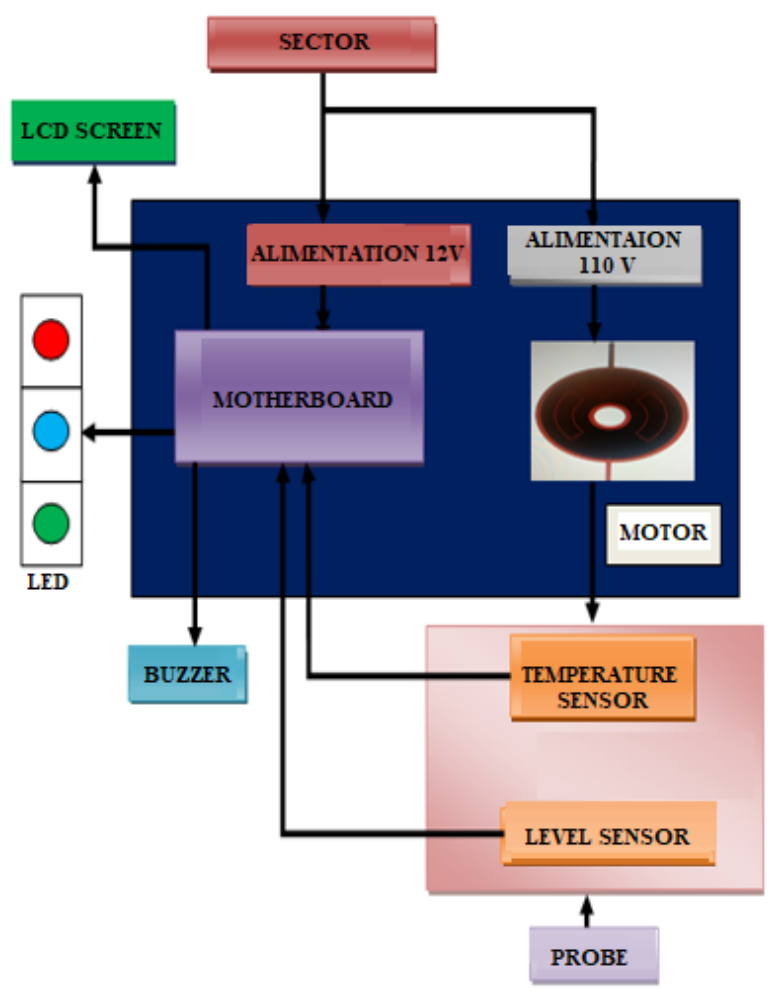

Figure 4: Block diagram of operation

\subsection{Principle of operation}

The designed Vacuum Cleaner uses the process of creating a partial vacuum to suck up body fluids during interventions through an electric motor. This engine is composed of an air inlet and outlet, which creates a vacuum thanks to a piston movable through electrical energy, which causes the creation of a vacuum to suck the air from the environment in which it is finding. The air inlet is connected to the central tubing which is subdivided into three channels, the first two of which are connected respectively to the manometer and the pressure regulator, the third channel is linked to the jar through an antibacterial filter. Then the jar is linked to the suction probe which is introduced into the incision area during the various surgical procedures.

When the device is powered on, the green LED will light up to indicate that the device is powered on. After five seconds, the pedal is operated to start the suction motor, then the liquid passes through the probe, while passing through the temperature sensor (LM35) flows into the fluid collection jar. All information on temperature and liquid level is analyzed by the Arduino board and displayed on the LCD screen. The multicolored LED lights up when the level is lower than the maximum which is 4 liters. On the control panel is also a pressure regulator which is linked to the third channel allowing increasing and decreasing the suction pressure of the liquid which causes the same variations in the level of the suction flow. These variations are visualized through the manometer. When the maximum level is reached, the multicolored LED goes out and the red LED lights up, then the Buzzer gives an audible alarm, which causes the automatic stop of the suction. The operating principle is shown schematically in figure 5 .

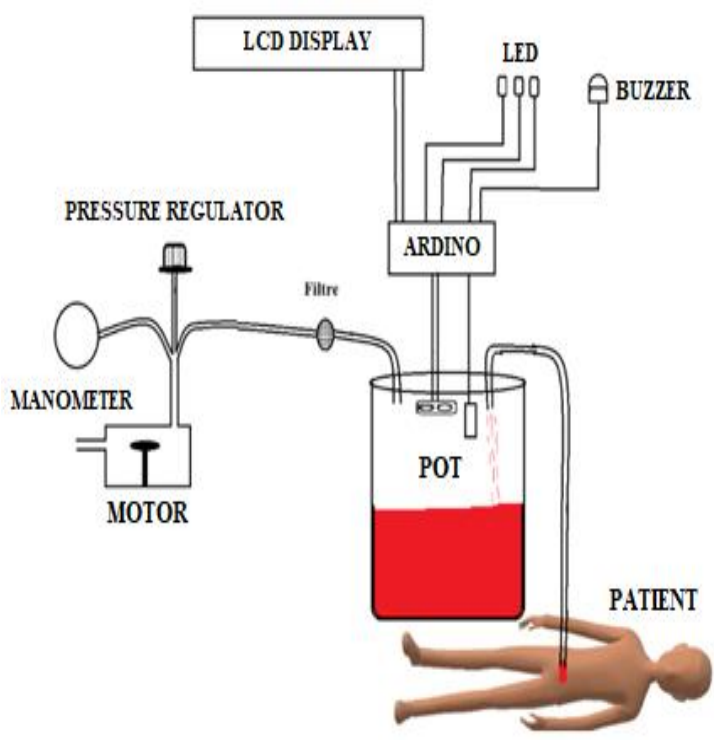

Figure 5: Diagram of the operating principle 
ISSN (online): 2581-3048

\subsection{Technical characteristics of the vacuum cleaner}

The technical characteristics of the designed vacuum cleaner are shown in Table 1.

Table 1: Technical characteristics of the vacuum cleaner

\begin{tabular}{|l|c|c|c|}
\hline Characteristics & Symbol & Value & Unit \\
\hline Voltage 220V & $\mathrm{U}$ & 220 & $\mathrm{~V}$ \\
\hline Intensity 3.5A & $\mathrm{I}$ & 3.5 & $\mathrm{~A}$ \\
\hline Frequency & $\mathrm{f}$ & $50 / 60$ & $\mathrm{~Hz}$ \\
\hline Power & $\mathrm{P}$ & 770 & $\mathrm{~W}$ \\
\hline Depression & $\mathrm{D}$ & 700 & $\mathrm{mmHg}$ \\
\hline Maximum flow at 50Hz & $\mathrm{Q}_{\max }$ & 18.33 & $\mathrm{1} / \mathrm{min}$ \\
\hline Maximum flow at 60Hz & $\mathrm{Q}_{\max }$ & 33.33 & $\mathrm{l} / \mathrm{min}$ \\
\hline Maximum pressure & $\mathrm{p}_{\max }$ & 3.5 & bars \\
\hline Maximum vacuum pressure & $\mathrm{p}_{\operatorname{mv}}$ & 200 & $\mathrm{mbars}$ \\
\hline Sound level & $\mathrm{Ns}$ & $\leq 60$ & $\mathrm{~dB}$ \\
\hline Jar capacity & $\mathrm{C}$ & 4 & $\mathrm{litre}$ \\
\hline Dimensions & $\mathrm{H} \times \mathrm{L} \times \mathrm{l}$ & $60 \times 32 \times 25$ & $\mathrm{~cm} \times \mathrm{cm} \times \mathrm{cm}$ \\
\hline Mass & $\mathrm{M}$ & 5 & $\mathrm{~kg}$ \\
\hline
\end{tabular}

The photos in figure 6 show the front side views of the vacuum cleaner produced.

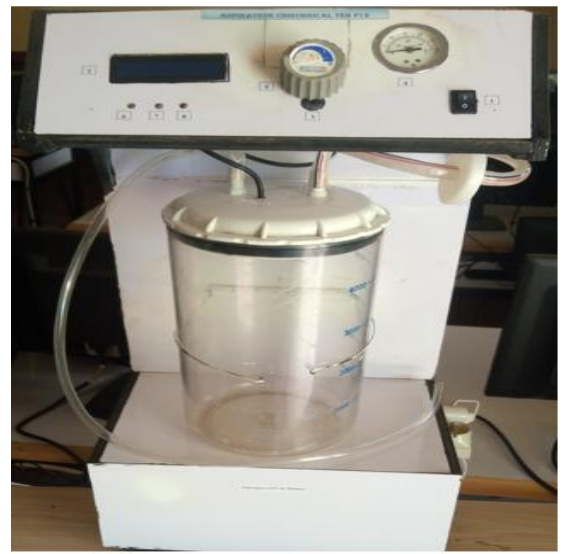

(a) Front view

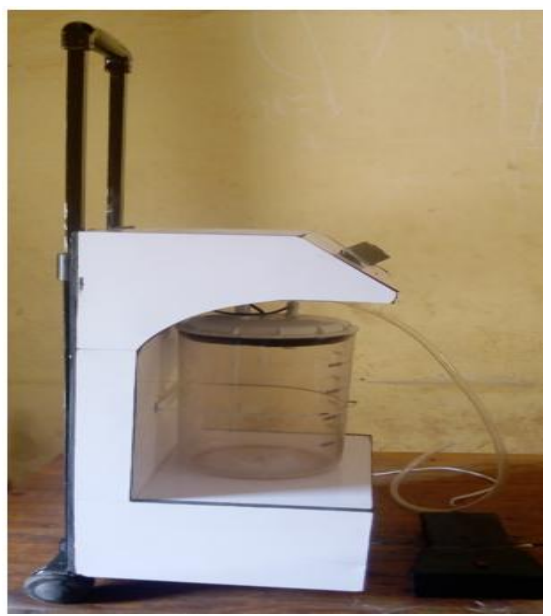

(b) Profile view

\section{CONCLUSION}

The surgical suction pump is a device used in health facilities, allowing the suction of body fluids during surgical procedures. Thus, most of our hospitals do not have this work equipment, motivated us to design and locally produce a prototype of this device. At the end of this study, we plan to continue the work by increasing the number of jars and by energy autonomy (solar and battery models).

\section{REFERENCES}

[1] ATMOS, Medizin Technik, Aspiration chirurgicale, ATMOS Médical France 3 Allée des Maraîchers 13013 Marseille, www.atmosmed.com, 24p.

[2] Rahi RASOULIFAR, Processus de conception centé utilisateur à base de scenario: Application à la conception d'instruments chirurgicaux innovants en chirurgie mini-invasive, Thèse de doctorat de l'Université Joseph Fourier - Grenoble, 242p, décembre 2009.

[3] Système de gestion des fluides, Serres Saga, Manuel de l'Utilisateur, www.serres.com, Français 6001138 rev $2.17 / 2019,99$ p, juillet 2019.

[4] Dieulafoy Georges, traité de l'aspiration des liquides morbides, Paris Masson, 1873.

[5] Martin JP. Les aspirateurs de liquides morbides. Clystère (www.clystere.com), n 37, 2015.

[6] Dr Jean-Pierre MARTIN, L'histoire des seringues, injecteurs et aspirateurs étudiées comme modèles de l'évolution technologie des instruments médicaux, Mémoire D.U Histoire de la Médecine de l'Université Paris Descartes, 436p, 2017-2018.

[7] TOUOMOU TCHOFFO Eric Landry, Conception et Réalisation d'un Aspirateur Chirurgical à trois bocauxavec batterie, Mémoire de fin d'Etude de cycle Licence de l'Université des Montagnes, Cameroun, 2015, 50p.

[8] République de Guinée, Ministère de la Santé, Etude de collecte des données dans le secteur de la santé en Guinée (Appui à la reconstruction après Ebola dans le secteur de la santé), Agence Japonaise de Coopération International, Rapport Final, 238p, mars 2017.

[9] Texas Instruments SG2524, SG3524 Regulating Pulse-Width Modulators, SLVS077F-April 1977 Revised, 30p, january 2021.

[10] LSU-Aspirateur de mucosités Laerdal, www.laerdal.com, 8187 Rev D Printed in Norway, Laerdal Medical AS. All rights reserved, 36p, 2011.

[11] Aspirateur Médical de Secrétions Boscarol, OB1000 FA - OB1000 FM, Rev. 08-2020 USMAN1000 2PFR, 28p, août 2020. 
ISSN (online): 2581-3048

Volume 5, Issue 4, pp 120-125, April-2021

https://doi.org/10.47001/IRJIET/2021.504018

\section{AUTHORS BIOGRAPHY}

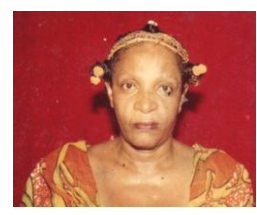

Pierre Louis Morpoo Rebeca, State Doctor of the Higher Institute of Medical Sciences of Havana. Teacher-researcher, Head of Biomedical Equipment Technology Department at the Higher Institute of Technology of Mamou, Guinea.

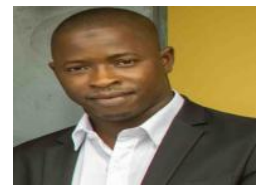

Thierno Ibrahima Barry, Biomedical Engineer, Teacherresearcher Deputy Head of Biomedical Equipment Technology Department at the Higher Institute of Technology of Mamou, Guinea. Ansoumane Sakouvogui, Doctor $\mathrm{Ph} . \mathrm{D}$, Teacher-researcher, Head of the Energy Department of the Higher Institute of Technology of Mamou, Guinea.
Cellou Kanté, Professor, Teacherresearcher, Director General of the Higher Institute of Technology of Mamou, Guinea.

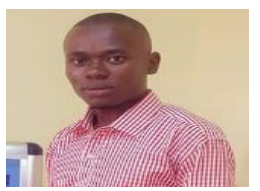

Mohamed Salif Camara, Engineer in Instrumentation and Physical Measurements, Teacher and researcher at the Higher Institute of Technology of Mamou, Guinea.

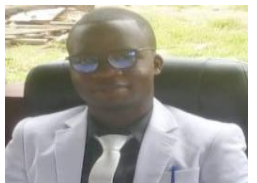

Daniel Mamy, Biomedical Engineer, Graduated in Biomedical Equipment Technology from the Higher Institute of Technology of Mamou, Guinea.

\section{Citation of this Article:}

Pierre Louis Morpoo Rebeca, Thierno Ibrahima Barry, Ansoumane Sakouvogui, Cellou Kanté, Mohamed Salif Camara, Daniel Mamy, "Design and Realization of a Surgical Aspirator" Published in International Research Journal of Innovations in Engineering and Technology - IRJIET, Volume 5, Issue 4, pp 120-125, April 2021. Article DOI https://doi.org/10.47001/IRJIET/2021.504018 